\title{
Cortisol Facilitates Ovine Fetal/Maternal Water Transfer
}

\author{
ROSEMARY D. LEAKE, ${ }^{(14)}$ HENDRIK STEGNER, SUE M. PALMER, GARY K. OAKES, AND \\ DELBERT A. FISHER \\ Departments of Pediatrics and Obstetrics, UCLA School of Medicine, Harbor/UCLA Medical Center, \\ Torrance, California, USA
}

\begin{abstract}
Summary
After the infusion of $500 \mathrm{ml} 20 \%$ mannitol to 12 pregnant ewes, we studied fetal plasma osmolality responses in chronically catheterized fetal lambs at 129-140 days' gestation. To compare the effects of arginine vasotocin (AVT) alone and AVT plus cortisol on fetal/maternal water transfer, the mannitol infusion was repeated during a 2-h fetal infusion of AVT alone $(7 \mu \mathrm{U} / \mathbf{k g} /$ $\mathrm{min})$ and during infusion of AVT with cortisol $(50 \mu \mathrm{g} / \mathrm{h})($ eight and six animals, respectively). The fetal osmolar response to maternal mannitol administration was compared to the response following the baseline mannitol study in the same sheep. In four of the ewes, an identical (sham) study was performed substituting $500 \mathrm{ml}$ normal saline for the mannitol infusion to the ewe.

Fetal AVT infusion significantly obtunded the fetal osmolality increment induced by maternal mannitol alone $[\mathrm{P}<0.001$, analysis of variance (ANOVA)]. Fetal AVT administered concurrently with cortisol produced an increment in fetal plasma osmolality in response to maternal mannitol that was significantly enhanced compared with that during fetal AVT infusion alone ( $P$ $<0.001$, ANOVA). The response to AVT with cortisol was similar to that following mannitol alone. Normal saline (sham protocol) produced no change in maternal or fetal osmolality. These results indicate that fetal AVT inhibits fetal to maternal water transfer following an osmotic stimulus to the ewe, while cortisol (infused with AVT) tends to counteract the inhibitory effect of AVT on fetal/maternal water transfer.
\end{abstract}

\section{Abbreviations}

ANOVA, analysis of variance

AVT, arginine vasotocin

Vizolyi and Perks (13) in 1974 and Manku et al. (6) in 1975 showed that arginine vasotocin (AVT) administered to the fetal side of the isolated guinea pig amnion inhibits water transfer from the fetal to maternal side $(6,13)$. The addition of cortisol (with AVT) to the medium bathing the fetal side reestablished fetal/maternal water transfer (6). We have previously shown that arginine vasopressin or arginine vasotocin (AVT) infusion to the ovine fetus inhibits fetal/maternal water transfer following an osmolar challenge (mannitol infusion) to the ewe (4). In this study, to assess the effect of cortisol, we compared the fetal osmolar response to mannitol when either AVT or AVT plus cortisol is infused to the fetus.

\section{MATERIALS AND METHODS}

Femoral venous and arterial catheters were inserted under local anesthesia into date-bred, healthy (Columbia-Suffolk) ewes with singleton fetuses of 124 to 129 days' gestation. A maternal hysterotomy was conducted under ketamine anesthesia. The fetal hind limb was exteriorized, and catheters were inserted into the dorsal vein and artery and advanced to the site of maximal circulation. The fetus was then replaced in the uterus, the fetal catheters were exteriorized to a pouch attached to the flank of the ewe, and the uterus and maternal abdominal wall were closed. Catheters were maintained patent with a dilute heparin solution.

Chloramphenicol was given intravenously for 5 days to the ewe (500 $\mathrm{mg}$ ) and fetus $(25 \mathrm{mg}$ ); in addition, the drug was injected into the amniotic fluid $(500 \mathrm{mg}$ ) for 5 days postoperatively. Animals were maintained in indoor pens and had ad libitum access to baled alfalfa and water. Six to 7 days were allowed for recovery from surgery before studies were conducted. Gestational age at the time of the studies ranged from 129-140 days.

On the day of study, drinking water was removed from the cage. Studies were conducted only if the fetal pH exceeded 7.35. With the ewe standing, $50 \mathrm{ml}$ whole blood were removed from the maternal circulation into a heparinized syringe (1 unit heparin/4 cc blood) for subsequent fetal replacement transfusion.

Three study protocols were utilized. Each protocol included three baseline blood samples ( $4 \mathrm{ml}$ each) obtained at 10 -min intervals and additional blood samples every 10 min throughout the remainder of the study period. For plasma osmolality measurements, samples were obtained from the femoral arterial catheters of 12 ewes and the dorsal arterial catheters of the fetuses. All samples were collected after an aliquot of blood equivalent to the 4-ml dead space in the catheter was withdrawn. In Protocol I (mannitol control), after the baseline blood samples were obtained, $500 \mathrm{ml}$ mannitol (Osmitrol, 20\% solution, Travenol Laboratories, Inc, Deerfield, IL) were infused via the maternal femoral venous catheter over $15 \mathrm{~min}$. Beginning $10 \mathrm{~min}$ after the start of the mannitol infusion, five ( $4 \mathrm{ml}$ ) blood samples were obtained from the maternal and fetal arterial catheters at $10-\mathrm{min}$ intervals. Each sample was replaced with an equivolemic quantity of isotonic saline to the ewe and an equivolemic transfusion of maternal heparinized whole blood to the fetus.

Protocol II (mannitol plus AVT) was performed in the same animals. After obtaining three baseline blood samples at 10-min intervals, AVT $(7 \mu \mathrm{U} / \mathrm{kg} \cdot \min )$ was infused for $2 \mathrm{~h}$ into the fetal dorsal venous catheter of eight animals. Blood samples $(4 \mathrm{ml}$ from the fetus and $5 \mathrm{ml}$ from the ewe) were obtained every 10 min throughout the AVT infusion period. Maternal and fetal samples were replaced with saline and maternal blood, respectively, as described. At the completion of the 1 st $h$ of AVT infusion, mannitol was infused over $15 \mathrm{~min}$ into the maternal ewe via the venous catheter in a manner identical to Protocol I.

In Protocol III (mannitol plus AVT and cortisol) performed before or subsequent to Protocol I (mannitol control), AVT (7 
$\mu \mathrm{U} / \mathrm{kg} \cdot \mathrm{min}$ ) was infused into eight of the fetuses for $2 \mathrm{~h}$. Cortisol $(50 \mu \mathrm{g} / \mathrm{h})$ was added to the infusate for the last $90 \mathrm{~min}$. Mannitol was infused to the ewe over a 15 -min period at the beginning of the second h of the AVT infusion (Fig. 1).

In four of the animals, an additional (sham) study was performed prior to or subsequent to Protocols I, II, and III. In the sham protocol, blood sampling was conducted as described in the fetus and ewe during and after a 500-ml maternal infusion of isotonic saline. Maternal and fetal plasma osmolalities were measured as in Protocols I, II, and III. Data from the mannitol alone, mannitol plus AVT, and sham protocols were published previously (4).

Four-ml whole blood samples were collected in iced tubes containing $15 \%$ EDTA. All samples were spun at $1200 \times g$ in a refrigerated centrifuge, and the plasma separated. One-ml plasma samples were stored at $-20^{\circ} \mathrm{C}$ for measurement of osmolality by freezing point depression using an Advanced Instruments 3R precision osmometer.

Each protocol was analyzed as a single, independent experiment. Mean $( \pm$ SEM) values for the three baseline $(-20,-10$, $+0 \mathrm{~min})$ and five postmannitol $(+10,+20,+30,+40,+50 \mathrm{~min})$ measurements of fetal plasma osmolality were compared using the paired $t$ test. Comparisons between groups for Protocols I, II, and III were made by two-way ANOVA.

\section{RESULTS}

Mean ( \pm SEM) fetal plasma osmolalities during various study periods are shown in table 1 . Normal saline infusion to the ewe (sham protocol) did not alter fetal plasma osmolality (mean of three baseline values versus postmannitol values $=286 \pm 1.8$ versus $285 \pm 2.3 \mathrm{mOsm} / \mathrm{kg}$ ). During the baseline period $(-20$, $-10+0 \mathrm{~min})$, mean $( \pm \mathrm{SEM})$ fetal plasma osmolality values were similar for the mannitol alone (Protocol I), mannitol plus AVT (Protocol II), and mannitol plus AVT and cortisol (Protocol III) studies $(292 \pm 2.1,289 \pm 3.0$, and $290 \pm 2 \mathrm{mOsm} / \mathrm{kg}$, respectively). Mean ( \pm SEM) fetal plasma osmolality results during the $1 \mathrm{~h}$ of AVT or AVT plus cortisol infusions (prior to mannitol) did not change $(292 \pm 3.4$ versus $294 \pm 4.0 \mathrm{mOsm} /$ $\mathrm{kg}$, respectively). Mannitol infusion to the ewe (Protocol I) produced a significant increase in mean fetal plasma osmolality during the $1 \mathrm{~h}$ following mannitol $(292 \pm 2.1$ to $306 \pm 4.1$ $\mathrm{mOsm} / \mathrm{kg} ; P<0.05)$. Mannitol infused during AVT infusion to the fetus (Protocol II) produced a slight, albeit insignificant, fetal osmolar response ( $292 \pm 3.4$ to $298 \pm 3.0 \mathrm{mOsm} / \mathrm{kg}$ ). Mannitol given during the fetal AVT plus cortisol infusions (Protocol III) produced an increment in fetal plasma osmolality similar to that of mannitol alone $(294 \pm 4.0$ to $307 \pm 5.0 \mathrm{mOsm} / \mathrm{kg})$. Thus, the fetal plasma osmolar responses following mannitol alone and mannitol during fetal AVT plus cortisol infusions were similar (NS; two-way analysis of variance). Moreover, each was significantly greater than the response to mannitol observed during the fetal infusion of AVT without cortisol ( $\mathrm{P}<0.001$, ANOVA). Figure 2 shows the mean fetal plasma osmolar change from baseline $(\Delta \mathrm{mOsm} / \mathrm{kg})$ for each of the study protocols during the hour following mannitol infusion.

\section{DISCUSSION}

In the present in vivo study, we observed that the addition of cortisol to a fetal AVT infusion reverses the previously reported (4) inhibitory effect of AVT on water transfer from the fetal to the maternal circulation. In in vitro studies, Vizsolyi and Perks (13) and Manku et al. (6) described a similar effect of cortisol in reversing the inhibitory effect of AVT on water transfer from the fetal to maternal sides of the isolated guinea pig amnion. Moreover, Vizsolyi and Perks (13) and Horrobin et al. (2) showed that cortisol administered alone to the fetal side of the in vitro guinea pig amnion augmented fetal to maternal water flow. Thus, cortisol appears to inhibit the AVT effect by stimulating a counteracting fetal/maternal water flux rather than "blocking" the inhibitory effect of AVT on fetal/maternal flow. The exact mechanism whereby cortisol modulates water exchange across the placental membrane is unclear.

It is known that cortisol plays a permissive role in water diuresis in the kidney (3). Patients with adrenal insufficiency, for example, cannot excrete a water load normally (10). Cortisol restores this ability (1) and when given in pharmacologic doses, further increases free water excretion (9). Cortisol also is necessary for the maintenance of optimal glomerular filtration rate and renal blood flow. The impaired water excretion in adrenalectomized dogs does not seem to be due to vasopressin; arginine vasopressin secretion is normal in these animals (5). Moreover, these dogs have a shift of water from the extracellular to the intracellular compartment, and this shift is reversible with hydrocortisone treatment (5). The effect of cortisol on water balance

\section{PROTOCOL III}

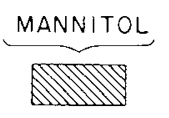

\begin{tabular}{|c|}
\hline CORTISOL TO FETAL CIRCULATION \\
\hline AVT TO FETAL CIRCULATION \\
\hline
\end{tabular}

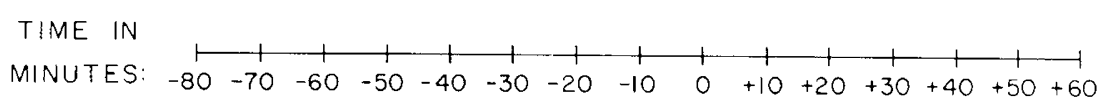

Fig. 1. Schematic representation of Protocol III: maternal mannitol plus fetal AVT and cortisol infusions.

Table 1. Mean ( \pm SEM) fetal plasma osmolalities during various study periods

\begin{tabular}{lcccc} 
& Baseline & $\begin{array}{c}\text { Posthormone } \\
\text { infusion }\end{array}$ & Postsaline & Postmannitol \\
\hline Sham protocol & $286 \pm 1.8$ & & $285 \pm 2.3$ & $306 \pm 4.1$ \\
Mannitol & $292 \pm 2.1$ & & $298 \pm 3.0$ \\
AVT and mannitol & $289 \pm 3.0$ & $292 \pm 3.4$ & & $307 \pm 5.0$ \\
AVT and cortisol and mannitol & $290 \pm 2.0$ & $294 \pm 4.0$ & & \\
\hline
\end{tabular}




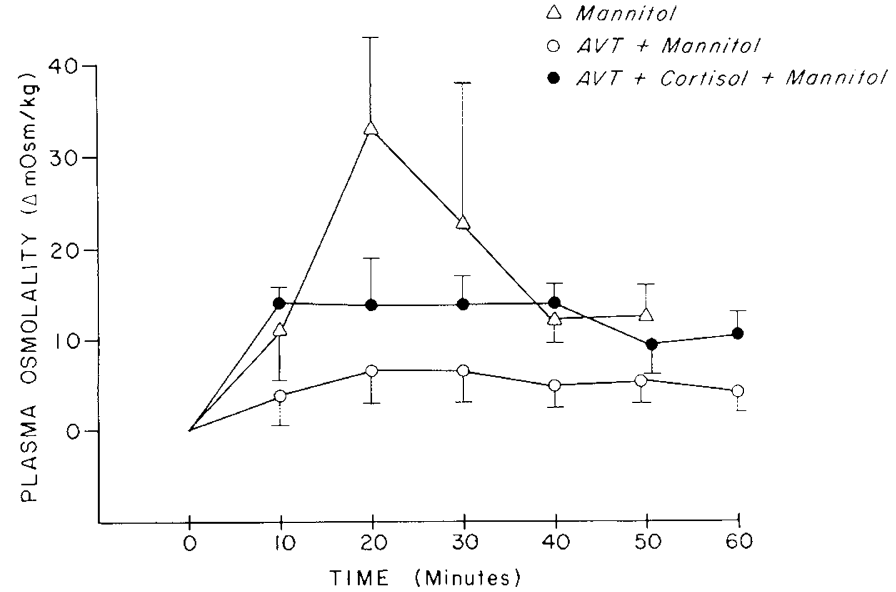

Fig. 2. Change from mean baseline fetal plasma osmolality ( $\Delta$ mOsm/ $\mathrm{kg}$ ) for the mannitol alone, mannitol plus fetal arginine vasotocin (AVT), or mannitol plus fetal AVT and cortisol infusions. Each point represents the mean $( \pm$ SEM) of values obtained at the time indicated on the horizontal.

is not limited to the kidney, but includes a more generalized effect on body water distribution in the $\operatorname{dog}(7,8,12)$.

The present data taken with earlier studies support the view that fetal/maternal water exchange is influenced at several levels by fetal pituitary and adrenal hormones. It is apparent from our studies in sheep, that arginine vasopressin, arginine vasotocin, and cortisol levels in fetal serum each can affect transplacental water flux (4). Vizolyi and Perks (13) and Manku et al. (6) showed that AVT inhibited water transfer across the guinea pig amnion whereas cortisol augmented water transfer (6). In the sheep model, water flow from the amniotic cavity to the maternal circulation is independent of amniotic fluid arginine vasopressin or AVT concentrations (11). However, prolactin instilled into amniotic fluid of the sheep inhibits mannitol-induced amniotic to maternal water flow (11). These data document a significant degree of fetal control of fetal/maternal water exchange during pregnancy in mammals. There seems to be some species variation in the hormones and sites of action.

\section{REFERENCES AND NOTES}

1. Dingman JF, Streeten DHP, and Thorn GW 1957 Effect of cortisone on the abnormal distribution of intravascular water in adrenal cortisol insufficiency in man. J Lab Clin Med 49:7

2. Horrobin DF, Manku MS, Robertshaw D 1973 Water-losing action of antidiuretic hormone in the presence of excess cortisol: restoration of normal action by prolactin or by oxytocin. J Endocrinol 58:135

3. Kleeman CR, Levi J, Better O 1975 Kidney and adrenocorticol hormones. Nephron 15:261

4. Leake RD, Stegner H, Palmer SM, Oakes GK, Fisher DA 1983 Arginine vasopressin and arginine vasotocin inhibit ovine fetal/maternal water transfer. Pediatr Res 17:583

5. Levi J, Grinblat J, Kleeman CR 1973 Water diuresis in the volume expanded glucocorticoid-deficient dog. Isr J Med Sci 9:429

6. Manku MS, Mtaboji JP, Horrobin DF 1975 Effect of cortisol, prolactin, and ADH on the amniotic membrane. Nature 258:78

7. Higgins JT, Mulrow PJ 1972 Fluid and electrolyte disorders of endocrine diseases. In: Maxwell MH, Kleeman CR (eds) Clinical Disorders of Fluid and Electrolyte Metabolism. McGraw-Hill, New York, pp 1291-1338

8. McNeil IF, Dixon JP, Moore FD 1963 The effects of hemorrhage and hormones on the partition of body water in the adrenalectomized dog. J Surg Res 3:344

9. Raisz LG, McNeely WF, Saxon L, Rosenbaum JD 1957 The effects of cortisone and hydrocortisone on water diuresis and renal function in man. J Clin Invest 36:767

10. Robinson FJ, Power MH, Kepler EJ 1941 Two new procedures to assist in recognition and exclusion of Addison's disease: a preliminary report. Proc Staff Meet Mayo Clin 16:577

11. Ross MG, Leake RD, Ervin MG, Oakes GK, Hobel CC, Fisher DA 1983 Bulk flow of amniotic fluid water in response to a maternal osmotic challenge. Am J Obstet Gynecol, 147:697

12. Tucci JP, Lawler DP 1972 Water, electrolyte, and acid-base disorders in diseases of the adrenal cortex and thyroid gland. In: Maxwell MH, Kleeman CR (eds) Clinical Disorders of Fluid and Electrolyte Metabolism. McGraw-Hill, New York, pp 923-970

13. Vizsolyi E Perks AM 1974 The effect of arginine vasotocin on the isolated amniotic membrane of the guinea pig. Can J Zool 52:371

14. Requests for reprints should be addressed to: Dr. Rosemary D. Leake, Dept of Pediatrics, Harbor/UCLA Medical Center, 1000 West Carson Street Torrance CA 90509

15. This research was supported by United States Public Health Service Grant HD 06335 from the National Institute of Child Health and Human Development. 16. Accepted for publication April 12,1983. 